\title{
Health Coaching by Medical Assistants to Improve Control of Diabetes, Hypertension, and Hyperlipidemia in Low-Income Patients: A Randomized Controlled Trial
}

Rachel Willard-Grace, MPH

Ellen H. Chen, $M D^{1,2}$

Danielle Hessler, PbD, MS

Denise DeVore'

Camille Prado ${ }^{4}$

Thomas Bodenheimer, $M D, M P H^{1}$

David H. Thom, MD, $P b D^{1}$

'Department of Family and Community Medicine, University of California San

Francisco, San Francisco, California

${ }^{2}$ Silver Avenue Family Health Center, San Francisco Department of Public Health, San Francisco, California
AC Annals Journal Club selection; see inside back cover or http://www. annfammed.org/AJC/.

Conflicts of interest: authors report none.

\section{CORRESPONDING AUTHOR}

Rachel Willard-Grace, MPH

University of California San Francisco

Department of Family \& Community

Medicine

1001 Potrero Ave, Ward 83

San Francisco, CA 94114

willardr@fcm.ucsf.edu

\begin{abstract}
PURPOSE Health coaching by medical assistants could be a financially viable model for providing self-management support in primary care if its effectiveness were demonstrated. We investigated whether in-clinic health coaching by medical assistants improves control of cardiovascular and metabolic risk factors when compared with usual care.
\end{abstract}

METHODS We conducted a 12-month randomized controlled trial of 441 patients at 2 safety net primary care clinics in San Francisco, California. The primary outcome was a composite measure of being at or below goal at 12 months for at least 1 of 3 uncontrolled conditions at baseline as defined by hemoglobin $A_{1 c}$, systolic blood pressure, and low-density lipoprotein (LDL) cholesterol. Secondary outcomes were meeting all 3 goals and meeting individual goals. Data were analyzed using $\chi^{2}$ tests and linear regression models.

RESULTS Participants in the coaching arm were more likely to achieve both the primary composite measure of 1 of the clinical goals ( $46.4 \%$ vs $34.3 \%, P=.02)$ and the secondary composite measure of reaching all clinical goals $(34.0 \%$ vs $24.7 \%, P=.05)$. Almost twice as many coached patients achieved the hemoglobin $A_{1 c}$ goal $(48.6 \%$ vs $27.6 \%, P=.01)$. At the larger study site, coached patients were more likely to achieve the LDL cholesterol goal $(41.8 \%$ vs $25.4 \%, P=.04)$. The proportion of patients meeting the systolic blood pressure goal did not differ significantly.

CONCLUSIONS Medical assistants serving as in-clinic health coaches improved control of hemoglobin $A_{1 c}$ and LDL levels, but not blood pressure, compared with usual care. Our results highlight the need to understand the relationship between patients' clinical conditions, interventions, and the contextual features of implementation.

Ann Fam Med 2015;13:130-138. doi: 10.1370/afm.1768.

\section{INTRODUCTION}

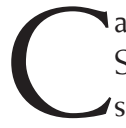
ardiovascular disease is the leading cause of death in the United States, ${ }^{1}$ and it accounts for more than $\$ 500$ billion of health care spending annually. ${ }^{2}$ Despite the demonstrated effectiveness of pharmaceutical therapies and lifestyle modifications for improving cardiovascular disease outcomes, $50 \%$ of people with hypertension, $43 \%$ with diabetes, and $80 \%$ with hyperlipidemia have not reached their goals for blood pressure, glycemic control, or lipids, respectively.-5 One-half of patients do not take their chronic disease medications as prescribed, and only 1 in 10 patients follow recommended guidelines for lifestyle changes, such as smoking cessation or weight loss. ${ }^{6}$ Minority and low-income communities bear a disproportionate burden of chronic disease and its complications, ${ }^{7}$ and they are less likely to engage in effective self-management of their conditions. ${ }^{8,9}$

Contributors to this gap in self-management include a lack of patient understanding of, and agreement with, the care plan, and low confidence and motivation to make healthy choices. Health coaching addresses this 
gap by equipping people with the knowledge, skills, and confidence to manage their chronic conditions. ${ }^{10}$

With primary care clinicians in increasingly short supply ${ }^{11}$ and overwhelmed by the expanding preventive and chronic care needs of their growing patient populations, ${ }^{12,13}$ new evidence-based models of care are needed to provide self-management support through other members of the care team. To be effective, this support must be culturally appropriate and financially sustainable in resource-poor settings. Medical assistants represent an untapped resource for health coaching. One of the fastest-growing allied health professions ${ }_{1}^{14}$ the medical assistant workforce is more culturally and linguistically concordant with patient populations than are other medical professions. ${ }^{15}$

Previous studies of medical assistant healthcoaching programs found positive trends in clinical indicators such as hemoglobin $\mathrm{A}_{\mathrm{cc}}\left(\mathrm{HbA}_{\mathrm{lc}}\right)$ but lacked power to find statistically significant differences, ${ }^{16}$ or were not designed as randomized trials. ${ }^{17-19}$ They focused on a single condition such as diabetes or hypertension. ${ }^{16-19}$ Medical assistant health coaching could be a viable model for providing self-management support in primary care if its effectiveness were demonstrated across the most prevalent cardiovascular conditions. We conducted a randomized controlled trial to test the effectiveness of clinic-based medical assistant health coaching vs usual care to improve clinical indicators among low-income patients with uncontrolled type 2 diabetes, hypertension, and hyperlipidemia.

\section{METHODS}

A description of the study sites, recruitment protocol, and participant demographics of this trial, conducted between 2011 and 2013, has been previously published. ${ }^{20}$ The protocol was approved by the University of California, San Francisco Committee on Human Research (approval number 10-02813), and the study was registered with clinicaltrials.gov (NCT01220336).

\section{Setting and Participants}

Participants were enrolled from 2 sites within the safety net of primary care clinics that serve San Francisco's low-income population. Clinic A was a not-forprofit federally qualified health care center serving a predominantly Latino population (89\%), with many uninsured patients (79\% of adults). Clinic B was a public primary care clinic whose patient population was predominantly African American (64\%) and publicly insured (73\%). Neither clinic had used a medical assistant health-coaching model before.

Potential participants were identified through chronic disease registries and billing data. They met at least 1 of 3 clinical criteria: (1) uncontrolled diabetes if they had an $\mathrm{HbA}_{\mathrm{cc}}$ of at least $8.0 \%$ in the last 3 months $_{i}(2)$ uncontrolled hypertension if they had a systolic blood pressure (SBP) of at least $140 \mathrm{~mm} \mathrm{Hg}$ at baseline and at the previous visit 2 weeks to 1 year before baseline; or (3) uncontrolled hyperlipidemia if they had a low-density lipoprotein (LDL) cholesterol level of at least $160 \mathrm{mg} / \mathrm{dL}$ (if not diabetic) or at least $100 \mathrm{mg} / \mathrm{dL}$ (if diabetic) within the past 6 months. If triglycerides were $40 \mathrm{mg} / \mathrm{dL}$ or lower, or were at least $400 \mathrm{mg} / \mathrm{dL}$, then non-high-density lipoprotein (HDL) cholesterol (total cholesterol minus high-density lipoprotein cholesterol) was used to determine eligibility, with thresholds of at least $190 \mathrm{mg} / \mathrm{dL}$ and at least 130 $\mathrm{mg} / \mathrm{dL}$ for nondiabetic and diabetic patients, respectively. ${ }^{21}$ Additional eligibility criteria included being between the ages of 18 to 75 years, having had at least 1 visit within the past 12 months, and planning to attend the clinic for the next 12 months (Figure 1). Primary care clinicians were asked to identify patients who should be excluded because of serious health conditions or behavioral health issues such as uncontrolled schizophrenia that would preclude working with a health coach $(3.7 \%$ of patients screened).

\section{Health Coach Training}

The 3 health coaches had diplomas from 3 - to 12 -month medical assistant programs, were women aged younger than 40 years, self-identified as Latina, and were bilingual in English and Spanish. None had graduated from a 4-year college. All received 40 hours of health coach training (Table 1), details of which have been previously published..$^{10,20,22,23}$ The health coaches were embedded as part of the care team at their clinic: 2 were placed at site $\mathrm{A}$ and 1 at site $\mathrm{B}$.

\section{Enrollment and Randomization}

Patients were approached by letter, telephone, and in person to be further screened and invited to take part in the study. All participants provided informed consent. A random binary sequence, stratified by diabetes diagnosis but not by site, was used to order study arm assignment into sequentially numbered envelopes. Research assistants conducted a 45 -minute verbal interview and updated clinical measures. Patients then opened the next envelope in the sequence, assigning them to health coaching or usual care. Participants received $\$ 10$ for each interview.

\section{Intervention}

Patients assigned to the coaching (intervention) arm received 12 months of coaching from the medical assistants trained as health coaches, who worked full time at the clinic sites. Following an established 
Figure 1. CONSORT diagram.

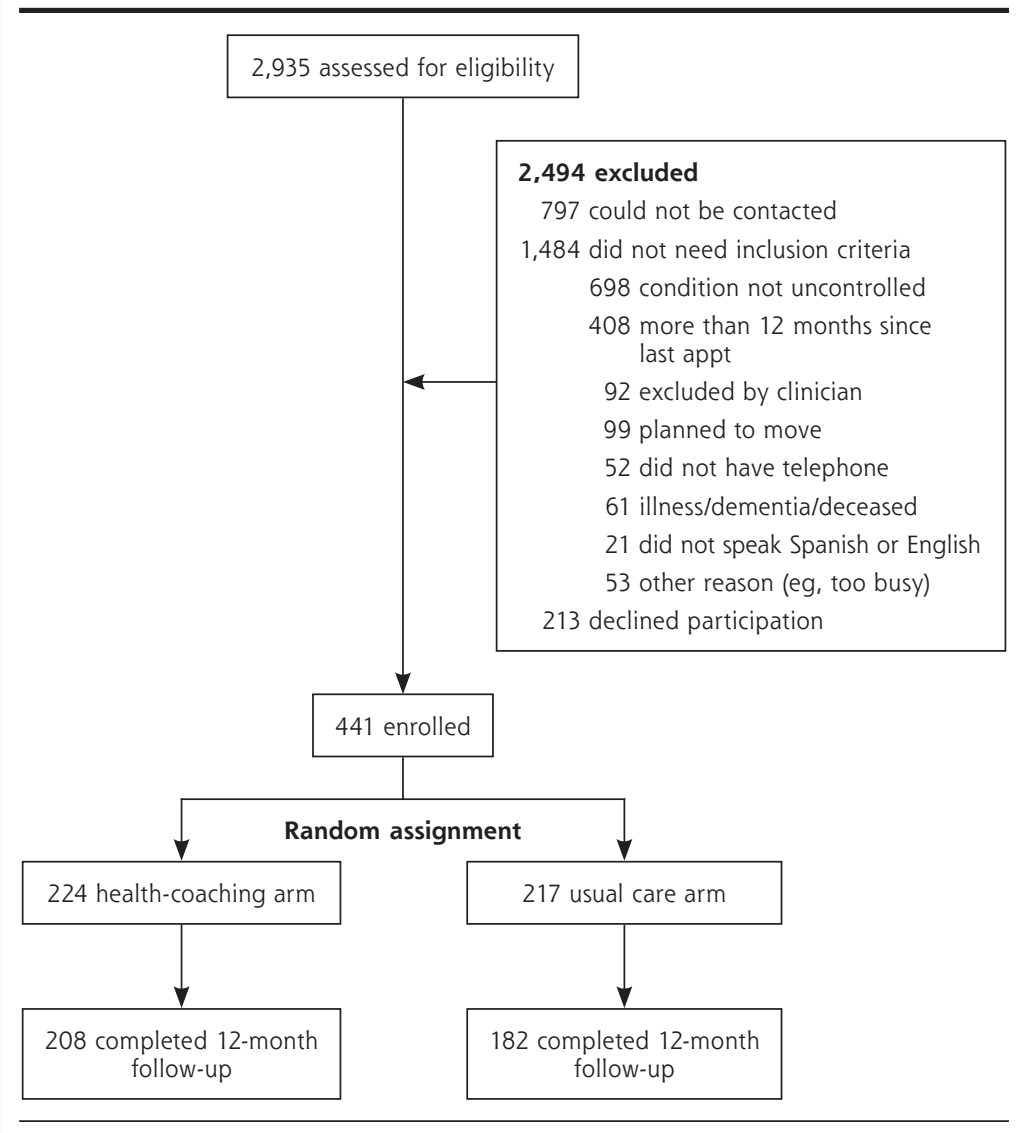

appt = appointment; CONSORT = Consolidated Standards of Reporting Trials.

model, ${ }_{1}^{22}$ health coaches met in the clinic with the patient before the visit, remained in the examination room during the visit, reviewed the care plan with the patient immediately after the visit, and followed up with patients between visits in person and by telephone. Health coaches were assigned up to 100 patients and instructed to contact them at least once a month and to have an in-person visit at least once every 3 months.

\section{Usual Care}

Patients randomized to usual care had access to any resources available at the clinic, including visits with their clinician, diabetes educators, nutritionists, chronic care nurses, educational classes, and registry data to plan care.

\section{Measures}

Interviews at baseline and 12 months captured demographics and other patientreported measures. $\mathrm{HbA}_{1 \mathrm{c}}$, blood pressure, lipid levels, weight, and height were col- lected at baseline and at 12 months using the same techniques. ${ }^{20}$ For diabetic patients, $\mathrm{HbA}_{1 \mathrm{c}}$ was measured using the NGSP-certified DCA Vantage point-of-care testing system (Siemens). ${ }^{24,25}$ Lipid panels (including calculated LDL) were measured by the clinical laboratory at site A using a Pentra 400 system (HORIBA Medical) and at site B using the Cholesterol Reference Method Laboratory Network (CRMLN)-certified CardioChek point-of-care testing system (PTS Diagnostics). ${ }^{26}$ Blood pressures were measured at enrollment and at 12 months by trained research assistants using a calibrated Omron Home Blood Pressure Monitor Model 711-AC (OMRON Healthcare). In accordance with American Heart Association guidelines, ${ }^{27}$ blood pressure was recorded as the average of 2 blood pressure readings, unless the 2 systolic readings differed by more than 5 points, in which case a third blood pressure reading was taken and the average of all 3 readings used.

\section{Outcomes}

A priori study goals were defined for $\mathrm{HbA}_{1 \mathrm{c}}(<8.0 \%)$, SBP $(<140 \mathrm{~mm}$ $\mathrm{Hg}$ if nondiabetic or $<130 \mathrm{~mm} \mathrm{Hg}$ if diabetic), and cholesterol (LDL cholesterol $<130 \mathrm{mg} / \mathrm{dL}$ or non-HDL cholesterol $<160 \mathrm{mg} / \mathrm{dL}$ if nondiabetic and LDL cholesterol $<100 \mathrm{mg} / \mathrm{dL}$ or non-HDL cholesterol $<130 \mathrm{mg} /$ $\mathrm{dL}$ if diabetic) among patients enrolled with uncontrolled diabetes, hypertension, and hyperlipidemia, respectively.
Table 1. Training of Health Coaches: Topics and Skills

\begin{tabular}{l|l}
\hline Collaborative communication & Medication adherence \\
Eliciting patient knowledge & Assessing patient knowledge and motivation \\
and motivation & Addressing barriers to adherence \\
Closing the loop (teach back) & Working with primary care clinicians \\
Setting the agenda & Taking notes during a visit \\
Reviewing laboratory numbers & Checking understanding \\
Action plans & Odfering help \\
Assessing patient motivations & Community and clinic resources \\
Exploring ambivalence & Behavior health \\
Disease-specific knowledge & Shysical activity and healthy eating \\
Basics of study conditions & Social determinants of health \\
Monitoring control &
\end{tabular}


The primary outcome was a composite ${ }^{28}$ of the proportion of patients in each arm reaching at least 1 of the above goals for which they were uncontrolled at baseline. Secondary outcomes were the proportion in each arm meeting goal for all conditions uncontrolled at baseline; the proportion meeting each of the individual goals; and the mean change in $\mathrm{HbA}_{1 \mathrm{c}}, \mathrm{SBP}$, and LDL cholesterol levels for patients enrolled with uncontrolled diabetes, hypertension, and hyperlipidemia, respectively.

\section{Sample Size Calculation}

Sample size and power calculations were performed for the primary composite measure. Enrolling 440 patients provided for more than $80 \%$ power to detect the estimated effect size of $15 \%$, after allowing for attrition of up to $20 \%$, using the standard threshold for a significant difference of .05 (2-sided).

\section{Statistical Analysis}

We compared differences between groups using independent sample $t$ tests and $\chi^{2}$ tests for continuous and categorical data, respectively. All analyses used the intent-to-treat principle in accordance with the Consolidated Standards of Reporting Trials (CONSORT) guidelines for reporting results from clinical trials. ${ }^{29}$ The change in continuous secondary outcomes was compared between study arms using linear regression models, with the composite and individual clinical outcomes as the outcome variables, and study arm as the predictor variable. Analyses were conducted on the total sample and by site. The role of site was further explored in multivariate linear and logistic regression models by controlling for site and examining the interaction between study arm and site on the primary and secondary outcomes. We initially analyzed the data as collected, without imputation for missing values (ie, used the missing-at-random approach). To assess the robustness of the results, we repeated the same analyses using multiple imputation to supply values for missing data. Because there were no meaningful differences between the results of the analyses with or without data imputation, we chose to present the results of the initial analysis using the missing-at-random (nonimputed) data. All statistical analyses were performed using SPSS 19.0 (SPSS Inc) except for imputation of missing data, conducted using NORM version 2 software (Pennsylvania State University) ${ }^{30}$ which imputes data through the expectation-maximization algorithm.

\section{RESULTS}

Of 654 patients identified as eligible, 441 (67.4\%) were enrolled, with 224 randomized to the healthcoaching group and 217 to the usual care group (Fig- ure 1). Three-quarters $(75.3 \%)$ of the participants were recruited from clinic site $\mathrm{A}$, and the remainder were recruited from clinic site B. Patients at clinic site A and Spanish speakers were more likely to participate in the study than patients from site B and English speakers.

Overall, the sample had a mean age of 53 years, and slightly more than one-half were women (Table 2). Many participants were first-generation immigrants and spoke Spanish as their primary language. About one-third reported their annual household income to be less than $\$ 5,000$. There were no significant baseline differences between the 2 intervention groups for any key variables, including the number of uncontrolled conditions or the proportion of patients in each arm with each condition. There were several differences between sites, however, (Table 3), with participants from site A more likely to report a primary language of Spanish and have lower education. Participants in the health-coaching arm received an average of 12.4 contacts with their health coach over the intervention period, with participants from site A receiving a greater number of contacts and reporting higher quality of health coach contacts.

Overall attrition was $11.6 \%$ from baseline to 12 months and was lower in the health-coaching arm than the usual care arm $(7.1 \%$ vs $16.1 \%, P=.003)$. Attrition status was not related to any demographic or outcome variable, and there were no significant between-group differences in attrition with the exception of baseline $\mathrm{HbA}_{1 \mathrm{c}}$, whereby participants who were lost to follow-up had higher baseline mean $\mathrm{HbA}_{1 \mathrm{c}}$ levels in the control arm than in the coaching arm $(10.5 \%[1.3 \%]$ vs $9.2 \%[0.4 \%], P=.03)$. Study clinical outcome measures $\left(\mathrm{HbA}_{1 \mathrm{c}}\right.$, LDL cholesterol, or SBP) were available for $94 \%$ (132) of 144 patients enrolled with uncontrolled diabetes, 95\% (156) of 165 patients enrolled with uncontrolled hypertension, and 83\% (169) of 203 patients enrolled with uncontrolled hyperlipidemia.

Participants in the health-coaching arm were more likely than those in the usual care arm to achieve both the primary composite measure of reaching at least 1 of their clinical goals and the secondary composite measure of reaching all of their clinical goals (Table 4). Additionally, almost twice the proportion of participants in the health-coaching arm achieved the $\mathrm{HbA}_{1 \mathrm{c}}$ study goal of $8.0 \%$ or lower. Differences in the primary and secondary composite goals and in 2 of 3 secondary goals (improvement in $\mathrm{HbA}_{1 \mathrm{c}}$ and LDL cholesterol) were significant at clinic site A but not at clinic site B. There were no significant differences in the proportion of participants meeting the SBP goal by study arm overall or when examined by clinic site. Essentially the same results were seen using imputed data, although the difference in the secondary composite measure for 
Table 2. Characteristics of Participants, Overall and by Study Arm

\begin{tabular}{|c|c|c|c|}
\hline \multirow[b]{2}{*}{ Characteristic } & \multirow{2}{*}{$\begin{array}{c}\text { All } \\
\text { Participants } \\
(\mathrm{N}=441)\end{array}$} & \multicolumn{2}{|c|}{ Study Arm } \\
\hline & & $\begin{array}{l}\text { Usual Care } \\
(n=217)\end{array}$ & $\begin{array}{l}\text { Health Coaching } \\
\quad(n=224)\end{array}$ \\
\hline \multicolumn{4}{|l|}{ Demographic characteristics } \\
\hline \multicolumn{4}{|l|}{ Clinic site, \% (No.) } \\
\hline Clinic site $A$ & $75.3(332)$ & $76.0(165)$ & $74.6(167)$ \\
\hline Clinic site B & 24.7 (109) & $24.0(52)$ & $25.4(57)$ \\
\hline Age, mean (SD), y & $52.7(11.1)$ & $52.9(11.5)$ & $52.6(10.7)$ \\
\hline Sex (female), \% (No.) & $55.3(244)$ & $52.2(127)$ & $58.5(117)$ \\
\hline Married/long-term relationship, \% (No.) & $53.1(234)$ & $57.1(124)$ & $49.1(110)$ \\
\hline Born in the United States, \% (No.) & $25.6(113)$ & $24.9(54)$ & $26.3(59)$ \\
\hline Years in United States, mean (SD) & $18.2(11.2)$ & $17.9(11.9)$ & $18.5(10.4)$ \\
\hline \multicolumn{4}{|l|}{ Primary language, \% (No.) } \\
\hline English & $27.7(122)$ & $26.7(58)$ & $28.6(64)$ \\
\hline Spanish & $68.7(303)$ & $69.5(151)$ & $67.9(152)$ \\
\hline Other & $3.6(16)$ & $3.7(8)$ & $3.6(8)$ \\
\hline \multicolumn{4}{|l|}{ Race/ethnicity, \% (No.) } \\
\hline Asian & $4.1(18)$ & $5.1(11)$ & $3.1(7)$ \\
\hline African American & $19.0(84)$ & $18.4(40)$ & $19.6(44)$ \\
\hline Latino or Hispanic & 70.1 (309) & $71.0(154)$ & $69.2(155)$ \\
\hline White & $2.5(11)$ & $2.3(5)$ & $2.7(6)$ \\
\hline Other & $4.3(19)$ & $3.2(7)$ & $5.4(12)$ \\
\hline \multicolumn{4}{|l|}{ Working status, \% (No.) } \\
\hline Full time & $18.6(82)$ & $16.1(35)$ & $21.0(47)$ \\
\hline Part time & $25.6(113)$ & $26.3(57)$ & $25.0(56)$ \\
\hline Homemaker & $13.8(61)$ & $17.1(37)$ & $10.7(24)$ \\
\hline Unemployed & $16.1(71)$ & $16.1(35)$ & $16.1(36)$ \\
\hline Retired/disabled/SSI/other & $25.9(114)$ & $24.3(53)$ & $27.2(61)$ \\
\hline \multicolumn{4}{|l|}{ Education, \% (No.) } \\
\hline$\leq 5$ th grade & $22.7(100)$ & $23.1(50)$ & $22.3(50)$ \\
\hline 6th to 8 th grade & $21.1(93)$ & $20.7(45)$ & $21.4(48)$ \\
\hline Some high school & $13.4(59)$ & $12.4(27)$ & $14.3(32)$ \\
\hline High school graduate or GED & $17.7(78)$ & $16.6(36)$ & $18.8(42)$ \\
\hline Some college & $15.6(69)$ & $19.4(42)$ & $12.1(27)$ \\
\hline College graduate & $9.5(42)$ & $7.8(17)$ & $11.2(25)$ \\
\hline \multicolumn{4}{|l|}{ Income, \% (No.) } \\
\hline$\leq \$ 5,000$ & $34.0(150)$ & $31.3(68)$ & $36.6(82)$ \\
\hline$\$ 5,000-\$ 10,000$ & $24.3(107)$ & $25.3(55)$ & $23.2(52)$ \\
\hline$\$ 10,000-\$ 20,000$ & $29.5(130)$ & $29.0(63)$ & $29.9(67)$ \\
\hline$\geq \$ 20,000$ & $12.2(54)$ & $14.2(31)$ & $10.2(23)$ \\
\hline $\begin{array}{l}\text { Number of PCP visits in year before } \\
\text { study, mean (SD) }\end{array}$ & $5.4(3.9)$ & $5.5(4.3)$ & $5.4(4.1)$ \\
\hline \multicolumn{4}{|l|}{ Clinical characteristics } \\
\hline BMI, mean (SD), kg/m² & $31.4(6.7)$ & $31.4(6.3)$ & $31.5(7.0)$ \\
\hline $\mathrm{HbA}_{1 \mathrm{c}}$ mean $(\mathrm{SD}), \%^{\mathrm{b}}$ & $9.9(1.5)$ & $10.0(1.4)$ & $9.8(1.5)$ \\
\hline LDL cholesterol, mean (SD), mg/dL & $147.0(35.6)$ & $147.8(34.1)$ & $146.3(36.9)$ \\
\hline $\mathrm{SBP}$, mean (SD), $\mathrm{mm} \mathrm{Hg}^{\mathrm{b}}$ & $159.4(15.4)$ & $160.9(16.8)$ & $157.7(13.5)$ \\
\hline \multicolumn{4}{|l|}{ Uncontrolled at baseline, \% (No.) } \\
\hline For 1 condition & $72.6(320)$ & $73.3(159)$ & $71.9(161)$ \\
\hline For 2 conditions & $23.6(104)$ & $23.5(51)$ & $23.7(53)$ \\
\hline For 3 conditions & $3.9(17)$ & $3.2(7)$ & $4.5(10)$ \\
\hline For $\mathrm{HbA}_{1 \mathrm{c}}$ & $35.8(158)$ & $33.6(73)$ & $37.9(85)$ \\
\hline For SBP & $43.5(192)$ & 46.5 (101) & $40.6(91)$ \\
\hline For cholesterol & $51.9(229)$ & $49.8(108)$ & $54.0(121)$ \\
\hline
\end{tabular}

the overall sample dropped from $9.3 \%$ to $7.2 \%$ and was no longer significant $(P=.10)$. Because of the introduction of new guidelines for SBP control for patients with diabetes, ${ }^{31}$ we conducted a post hoc analysis of the proportion of patients in each arm meeting the more recent standard of a value less than $140 \mathrm{~mm} \mathrm{Hg}$ that also found no statistically significant differences between arms.

A similar pattern was found when examining the mean change in $\mathrm{HbA}_{1 \mathrm{c}}$ and LDL cholesterol levels (Table 5), although the difference in change in LDL cholesterol levels was statistically significant only at clinic site A. There were no significant interactions between clinic and study arm.

\section{DISCUSSION}

This is the first randomized controlled trial we are aware of that is sufficiently powered to detect significant improvements in clinical indicators for patients receiving medical assistant health coaching compared with usual care. Patients who received health coaching were more likely to reach their goal for 1 or more of the conditions uncontrolled at baseline. They were also more likely to achieve control of all conditions. Almost twice the proportion of people in the healthcoaching group achieved goals for glycemic control compared with the usual care group, and at the larger site, people receiving coaching were more likely to achieve the LDL cholesterol goal. These findings are consistent with those of previous randomized controlled trials showing positive benefits for other models of self-management support using peers, registered nurses, or community health workers. ${ }^{32-35}$

Health coaching did not improve control of hypertension 
Table 3. Characteristics of Participants, Overall and by Clinic Site (continued)

\begin{tabular}{|c|c|c|c|c|}
\hline \multirow[b]{2}{*}{ Characteristic } & \multirow{2}{*}{$\begin{array}{l}\text { All } \\
\text { Participants } \\
(\mathrm{N}=441)\end{array}$} & \multicolumn{3}{|c|}{ Clinic Site } \\
\hline & & $\begin{array}{l}\text { Clinic Site A } \\
(\mathrm{n}=332)\end{array}$ & $\begin{array}{c}\text { Clinic Site B } \\
(n=109)\end{array}$ & $\begin{array}{c}P \\
\text { Value }\end{array}$ \\
\hline \multicolumn{5}{|l|}{ Clinical characteristics (continued) } \\
\hline \multicolumn{5}{|l|}{$\begin{array}{l}\text { Number of interactions by topic/ } \\
\text { activity addressed, mean (SD) }\end{array}$} \\
\hline Medications & $9.3(6.0)$ & $11.0(5.4)$ & $4.1(4.6)$ & $<.001$ \\
\hline Reviewing clinical values and goals & $7.4(4.6)$ & $8.4(3.9)$ & $4.5(5.2)$ & $<.001$ \\
\hline Discussing lifestyle changes & $7.4(5.0)$ & $9.1(4.3)$ & $2.1(2.2)$ & $<.001$ \\
\hline Agenda setting & $5.7(4.3)$ & $7.1(4.1)$ & $1.7(1.9)$ & $<.001$ \\
\hline Navigational support & $5.1(5.1)$ & $6.4(5.3)$ & $1.5(1.8)$ & $<.001$ \\
\hline Action plans for behavior change & $4.2(3.2)$ & $5.1(2.9)$ & $1.6(2.3)$ & $<.001$ \\
\hline Facilitating communication with PCP & $3.3(3.8)$ & $4.0(4.1)$ & $1.1(1.5)$ & $<.001$ \\
\hline Closing the loop (teach back) & $5.3(3.6)$ & $6.1(3.3)$ & $2.8(3.4)$ & $<.001$ \\
\hline $\begin{array}{l}\text { Patient-reported quality of health- } \\
\text { coaching interactions, mean (SD) }\end{array}$ & $3.3(0.7)$ & $3.4(0.5)$ & $2.8(0.9)$ & $<.001$ \\
\hline $\begin{array}{l}\text { Patient-reported trust in health } \\
\text { coach, mean (SD)c }\end{array}$ & $4.1(0.5)$ & $4.1(0.5)$ & $3.9(0.7)$ & $<.005$ \\
\hline \multicolumn{5}{|c|}{$\begin{array}{l}\mathrm{BMI}=\text { body mass index } ; \mathrm{GED}=\text { general equivalency diploma; } \mathrm{HbA}_{1 \mathrm{C}}=\text { hemoglobin } \mathrm{A}_{\mathrm{I} ;} \mathrm{LDL}=\text { low-density lipopro- } \\
\text { tein; } \mathrm{PCP}=\text { primary care physician; } \mathrm{SBP}=\text { systolic blood pressure; } \mathrm{SSI}=\text { supplemental security income. }\end{array}$} \\
\hline \multicolumn{5}{|c|}{$\begin{array}{l}\text { Includes only patients qualifying for the study on this measure ( } 158 \text { for } \mathrm{HbA}_{1 c}, 218 \text { for LDL cholesterol, and } 192 \\
\text { for SBP). } \\
\text { b On a scale of } 1 \text { to } 5 \text {, where } 5=\text { best. } \\
\text { ' On a scale of } 1 \text { to } 5 \text {, where } 5=\text { high. }\end{array}$} \\
\hline
\end{tabular}

Table 4. Primary Composite and Condition-Specific Outcomes by Study Arm, for Total Sample and by Clinic Site

\begin{tabular}{|c|c|c|c|c|}
\hline Outcome & $\begin{array}{l}\text { Health } \\
\text { Coaching, \% } \\
\text { (No.In) }\end{array}$ & $\begin{array}{l}\text { Usual } \\
\text { Care, \% } \\
\text { (No.In) }\end{array}$ & $\begin{array}{c}\text { Difference, \% } \\
(95 \% \mathrm{Cl})\end{array}$ & $\begin{array}{c}P \\
\text { Value }\end{array}$ \\
\hline \multicolumn{5}{|l|}{ Total sample } \\
\hline Composite (primary) ${ }^{\mathrm{a}}$ & $46.4(90 / 194)$ & $34.3(57 / 166)$ & 12.1 (2 to 23$)$ & .02 \\
\hline Composite (secondary) ${ }^{b}$ & $34.0(66 / 194)$ & $24.7(41 / 166)$ & 9.3 (1 to 19$)$ & .05 \\
\hline $\mathrm{HbA}_{1 c}$ goal achievedc & $48.6(36 / 74)$ & $27.6(16 / 58)$ & $21.0(5$ to 39$)$ & .01 \\
\hline Cholesterol goal achieved $^{d}$ & $42.7(41 / 96)$ & $32.0(24 / 75)$ & 10.7 (-4 to 25$)$ & .15 \\
\hline SBP goal achievede & $23.8(19 / 80)$ & $28.9(22 / 76)$ & $-5.1(-9$ to 19$)$ & .46 \\
\hline \multicolumn{5}{|l|}{ Clinic site A } \\
\hline Composite (primary) ${ }^{\mathrm{a}}$ & $49.7(73 / 147)$ & $32.8(42 / 128)$ & 16.9 (5 to 29$)$ & .01 \\
\hline Composite (secondary) $)^{b}$ & $36.1(53 / 147)$ & $24.2(31 / 128)$ & 11.9 (1 to 23$)$ & .03 \\
\hline $\mathrm{HbA}_{1 c}$ goal achievedc & $52.3(34 / 65)$ & $29.4(15 / 51)$ & 22.9 (5 to 41$)$ & .01 \\
\hline Cholesterol goal achieved ${ }^{d}$ & $41.8(33 / 79)$ & $25.4(16 / 63)$ & 16.4 (1 to 32$)$ & .04 \\
\hline SBP goal achievede & $25.5(12 / 47)$ & $31.9(15 / 47)$ & $-6.4(-11$ to 25$)$ & .49 \\
\hline \multicolumn{5}{|l|}{ Clinic site B } \\
\hline Composite (primary) ${ }^{\mathrm{a}}$ & $36.2(17 / 47)$ & $39.5(15 / 38)$ & $-3.3(-17$ to 24$)$ & .76 \\
\hline Composite (secondary) ${ }^{b}$ & $27.7(13 / 47)$ & $26.3(10 / 38)$ & $1.4(-18$ to 20$)$ & .89 \\
\hline $\mathrm{HbA}_{1 c}$ goal achievedc & $22.2(2 / 9)$ & $14.3(1 / 7)$ & $7.9(-31$ to 46$)$ & .69 \\
\hline Cholesterol goal achieved ${ }^{d}$ & $47.1(8 / 17)$ & $66.7(8 / 12)$ & $-19.6(-18$ to 56$)$ & .29 \\
\hline SBP goal achievede & $21.2(7 / 33)$ & $24.1(7 / 29)$ & $-2.9(-18$ to 24$)$ & .78 \\
\hline \multicolumn{5}{|c|}{$\begin{array}{l}\mathrm{HbA}_{1 \mathrm{c}}=\text { hemoglobin } \mathrm{A}_{1 \mathrm{C}} \mathrm{HDL}=\text { high-density lipoprotein; } \mathrm{LDL}=\text { low-density lipoprotein; } \mathrm{SBP}=\text { systolic blood pressure. } \\
\text { Note: Analyses used missing-at-random (nonimputed) data. See statistical analysis in Methods section for details. } \\
\text { a Achieved target for control of } 1 \text { or more of specific conditions for which patient was uncontrolled at baseline. } \\
{ }^{\mathrm{b}} \text { Achieved target for control of all conditions for which patient was uncontrolled at baseline. } \\
\text { " Goal was }<8.0 \% \text {. } \\
{ }^{\mathrm{d}} \text { Goal for diabetic patients was } \mathrm{LDL} \text { cholesterol }<100 \mathrm{mg} / \mathrm{dL} \text { or non-HDL cholesterol }<130 \mathrm{mg} / \mathrm{dL} \text { if triglycerides } \\
>400 \mathrm{mg} / \mathrm{dL} \text {, and for nondiabetic patients was } \mathrm{LDL} \text { cholesterol } \mathrm{I}<130 \mathrm{mg} / \mathrm{dL} \text { or non- } \mathrm{HDL} \text { cholesterol }<160 \mathrm{mg} / \mathrm{dL} \text { if } \\
\text { triglycerides }>400 \mathrm{mg} / \mathrm{dL} \text {. } \\
\text { e Goal was }<130 \mathrm{~mm} \mathrm{Hg} \text { for diabetic patients and }<40 \mathrm{~mm} \mathrm{Hg} \text { for nondiabetic patients. }\end{array}$} \\
\hline
\end{tabular}

patients. Attrition of patients, especially those with poor glycemic control, was greater in the usual care group however, these differences would result in a conservative estimate of the intervention effect.

Medical assistant health coaching has the potential to alleviate nationwide deficiencies in glucose, blood pressure, and cholesterol control even in an environment of deepening primary care clinician shortage. This model may satisfy several conditions needed for diffusion of innovation ${ }^{40}$ including relative advantage, compatibility, and scalability. As ubiquitous ${ }^{41}$ and relatively affordable ${ }^{42}$ members of the care team, medical assistants could provide critical self-management support even in resourcescarce settings. New payment models, such as capitated payments and shared savings, may allow health coaching to emerge as a means to produce positive clinical outcomes at lower costs. ${ }^{43}$ The medical assistant health-coaching model is acceptable to patients and clinicians. ${ }^{44,45}$ Because health coaches were dedicated staff who augmented clinic resources, the model had minimal impact on clinic flow, and the coaches off-loaded responsibilities from busy clinic staff. An ongoing cost analysis will be reported. Moreover, health coaching can help practices to satisfy requirements of patient-centered medical home accrediting agencies to provide patient self-management support. ${ }^{46}$ Scalability depends on the relative simplicity of implementing an intervention, which may be facilitated by crossorganizational exchange of training materials, workflows, and tools. 
Table 5. Secondary Condition-Specific Outcomes by Study Arm, for Total Sample and by Clinic Site

\begin{tabular}{|c|c|c|c|c|c|c|c|c|c|c|}
\hline \multirow[b]{2}{*}{ Outcome } & \multicolumn{4}{|c|}{ Health Coaching } & \multicolumn{4}{|c|}{ Usual Care } & \multirow{2}{*}{$\begin{array}{c}\text { Difference } \\
\text { Between Arms } \\
(95 \% \mathrm{Cl})\end{array}$} & \multirow[b]{2}{*}{$\begin{array}{c}P \\
\text { Value }\end{array}$} \\
\hline & $\mathrm{n}$ & $\begin{array}{l}\text { Baseline, } \\
\text { Mean (SD) }\end{array}$ & $\begin{array}{l}12 \text { Months, } \\
\text { Mean (SD) }\end{array}$ & DIM & $\mathrm{n}$ & $\begin{array}{l}\text { Baseline, } \\
\text { Mean (SD) }\end{array}$ & $\begin{array}{l}12 \text { Months, } \\
\text { Mean (SD) }\end{array}$ & DIM & & \\
\hline \multicolumn{11}{|l|}{ Total sample } \\
\hline $\mathrm{HbA}_{1 c}, \%$ & 74 & $\begin{array}{c}9.8 \\
(1.5)\end{array}$ & $\begin{array}{c}8.6 \\
(2.0)\end{array}$ & -1.2 & 58 & $\begin{array}{c}9.9 \\
(1.4)\end{array}$ & $\begin{array}{c}9.4 \\
(2.0)\end{array}$ & -0.5 & $\begin{array}{c}-0.7 \\
(-1.4 \text { to } 0.0)\end{array}$ & .06 \\
\hline LDL, mg/dL & 95 & $\begin{array}{l}147.2 \\
(36.3)\end{array}$ & $\begin{array}{l}119.3 \\
(52.8)\end{array}$ & -27.9 & 73 & $\begin{array}{l}143.4 \\
(33.2)\end{array}$ & $\begin{array}{l}125.4 \\
(39.1)\end{array}$ & -18.1 & $\begin{array}{c}-9.8 \\
(-21.6 \text { to } 2.0)\end{array}$ & .10 \\
\hline SBP, mm Hg & 80 & $\begin{array}{l}157.3 \\
(13.8)\end{array}$ & $\begin{array}{l}148.7 \\
(16.5)\end{array}$ & -8.6 & 76 & $\begin{array}{l}160.5 \\
(16.4)\end{array}$ & $\begin{array}{l}150.3 \\
(18.2)\end{array}$ & -10.2 & $\begin{array}{c}1.6 \\
(-7.6 \text { to } 4.4)\end{array}$ & .59 \\
\hline \multicolumn{11}{|l|}{ Clinic site A } \\
\hline $\mathrm{HbA}_{1 \mathrm{c},} \%$ & 65 & $\begin{array}{c}9.8 \\
(1.5)\end{array}$ & $\begin{array}{l}8.5 \\
(2.0)\end{array}$ & -1.3 & 51 & $\begin{array}{c}9.8 \\
(1.4)\end{array}$ & $\begin{array}{l}9.3 \\
(2.0)\end{array}$ & -0.6 & $\begin{array}{c}-0.7 \\
(-1.4 \text { to }-0.0)\end{array}$ & .04 \\
\hline $\mathrm{LDL}, \mathrm{mg} / \mathrm{dL}$ & 79 & $\begin{array}{l}148.2 \\
(38.3)\end{array}$ & $\begin{array}{l}122.6 \\
(55.1)\end{array}$ & -25.6 & 62 & $\begin{array}{l}145.0 \\
(35.0)\end{array}$ & $\begin{array}{l}130.5 \\
(37.6)\end{array}$ & -14.5 & $\begin{array}{c}-11.1 \\
(-23.9 \text { to } 1.7)\end{array}$ & .09 \\
\hline SBP, mm Hg & 47 & $\begin{array}{l}154.9 \\
(10.5)\end{array}$ & $\begin{array}{c}144.8 \\
(12.5)\end{array}$ & -10.0 & 47 & $\begin{array}{c}160.5 \\
(15.1)\end{array}$ & $\begin{array}{l}148.5 \\
(18.9)\end{array}$ & -12.0 & $\begin{array}{c}2.0 \\
(-5.1 \text { to } 9.0)\end{array}$ & .59 \\
\hline \multicolumn{11}{|l|}{ Clinic site B } \\
\hline $\mathrm{HbA}_{1 \mathrm{c}} \%$ & 9 & $\begin{array}{c}10.2 \\
(1.4)\end{array}$ & $\begin{array}{c}9.5 \\
(2.1)\end{array}$ & -0.7 & 7 & $\begin{array}{l}10.5 \\
(1.5)\end{array}$ & $\begin{array}{l}10.1 \\
(1.7)\end{array}$ & -0.5 & $\begin{array}{c}-0.2 \\
(-2.9 \text { to } 2.5)\end{array}$ & .89 \\
\hline LDL, mg/dL & 16 & $\begin{array}{l}142.8 \\
(29.4)\end{array}$ & $\begin{array}{l}103.6 \\
(37.8)\end{array}$ & -39.2 & 11 & $\begin{array}{l}136.9 \\
(29.2)\end{array}$ & $\begin{array}{c}98.6 \\
(36.9)\end{array}$ & -38.4 & $\begin{array}{c}-0.8 \\
(-31.3 \text { to } 29.6)\end{array}$ & .96 \\
\hline SBP, mm Hg & 33 & $\begin{array}{l}160.7 \\
(15.8)\end{array}$ & $\begin{array}{l}154.1 \\
(19.9)\end{array}$ & -6.6 & 29 & $\begin{array}{l}160.6 \\
(19.2)\end{array}$ & $\begin{array}{c}153.2 \\
(17.0)\end{array}$ & -7.4 & $\begin{array}{c}0.8 \\
(-10.0 \text { to } 11.6)\end{array}$ & .88 \\
\hline
\end{tabular}

$\mathrm{DIM}=$ difference in means; $\mathrm{HbA}_{1 \mathrm{C}}=$ hemoglobin $\mathrm{A}_{1 \mathrm{c}} \mathrm{LDL}=$ low-density lipoprotein; $\mathrm{SBP}=$ systolic blood pressure.

Note: Analyses used missing-at-random (nonimputed) data. See statistical analysis in Methods section for details.

Primary care practices struggle to provide selfmanagement support to their growing numbers of patients with chronic conditions. This medical assistant health-coaching model may provide an important answer to the barriers of time, resources, and cultural concordance faced by many primary care practices seeking to implement self-management support. Our study demonstrates that medical assistants can successfully serve as in-clinic health coaches to improve glycemic and cardiovascular health indicators over usual care.

To read or post commentaries in response to this article, see it online at http://www.annfammed.org/content/13/2/130.

Key words: medical assistants; allied health personnel; vulnerable populations; chronic disease management; health education; motivation; primary care; practice-based research

Submitted June 25, 2014; submitted, revised, October 6, 2014; accepted October 15, 2014.

Funding support: This study was supported by the Betty Irene Moore Nursing Initiative of the Gordon and Betty Moore Foundation.

Previous presentation: This work was previously presented in part at the Society for General Internal Medicine Annual Meeting, San Diego, California, April 23-26, 2014; at the American Diabetes Association Annual Conference, San Francisco, California, June 13-17, 2014; and at the North American Primary Care Research Group Annual Meeting, November 21-25, 2014, New York, New York.

Acknowledgments: This research is the result of close partnership with the leadership and staff of Mission Neighborhood Health Center and Southeast Health Center. Without the wisdom and expertise of their leadership, clinicians, and front-line staff, this study would not have been possible. Likewise, this study relied on the hard work of research assistants and medical assistant health coaches, including Marissa Pimentel, Christina Araujo, and Adriana Najmabadi. Lisa Strycker of the Oregon Research Institute assisted with data imputation. Finally, thank you to the patients who gave of their time and trust to help answer important questions about the role of health coaches in primary care.

\section{References}

1. Fryar CD, Hirsch R, Eberhardt MS, Yoon SS, Wright JD. NCHS Data Brief: Hypertension, high serum total cholesterol, and diabetes: racial and ethnic prevalence differences in U.S. adults, 1999-2006. http://www.cdc.gov/nchs/data/databriefs/db36.pdf. Published Apr 2010. Accessed Oct 1, 2013.

2. The Council of State Governments. Trends alert: Costs of chronic disease: what are states facing? http://www.healthystates.csg.org/ NR/rdonlyres/E42141D1-4D47-4119-BFF4-A2E7FE81C698/0/Trends Alert.pdf. Published 2006. Accessed Nov 15, 2012.

3. Egan BM, Zhao Y, Axon RN. US trends in prevalence, awareness, treatment, and control of hypertension, 1988-2008. JAMA. 2010; 303(20):2043-2050.

4. Cheung BMY, Ong KL, Cherny SS, Sham PC, Tso AW/K, Lam KSL. Diabetes prevalence and therapeutic target achievement in the United States, 1999 to 2006. Am J Med. 2009;122(5):443-453.

5. Ford ES, Li C, Pearson WS, Zhao G, Mokdad AH. Trends in hypercholesterolemia, treatment and control among United States adults. Int J Cardiol. 2010;140(2):226-235.

6. Haynes RB, McDonald HP, Garg AX. Helping patients follow prescribed treatment: clinical applications. JAMA. 2002;288(22): 2880-2883.

7. Centers for Disease Control and Prevention. National diabetes fact sheet. http://www.cdc.gov/diabetes/pubs/estimates11.htm. Published 2011. Accessed Nov 15, 2012.

8. Thackeray R, Merrill RM, Neiger BL. Disparities in diabetes management practice between racial and ethnic groups in the United States. Diabetes Educ. 2004;30(4):665-675. 
9. Bailey JE, Hajjar M, Shoib B, Tang J, Ray MM, Wan JY. Risk factors associated with antihypertensive medication nonadherence in a statewide Medicaid population. Am J Med Sci. 2014;348(5):410-415.

10. Ghorob A. Health coaching: teaching patients how to fish. Fam Pract Manag. 2013;20(3):40-42.

11. Petterson SM, Liaw WR, Phillips RL Jr, Rabin DL, Meyers DS, Bazemore AW. Projecting US primary care physician workforce needs: 2010-2025. Ann Fam Med. 2012;10(6):503-509.

12. Østbye T, Yarnall KSH, Krause KM, Pollak KI, Gradison M, Michener $\mathrm{JL}$. Is there time for management of patients with chronic diseases in primary care? Ann Fam Med. 2005;3(3):209-214.

13. Yarnall KSH, Pollak KI, Østbye T, Krause KM, Michener JL. Primary care: is there enough time for prevention? Am J Public Health. 2003; 93(4):635-641.

14. Bureau of Labor Statistics. Occupational Outlook Handbook 20102011. http://www.bls.gov/oco/ocos164.htm. Accessed Oct 1, 2013.

15. Chapman S, Marks A, Chan M; Center for the Health Professions. Research Brief: The increasing role of medical assistants in small primary care physician practice: key issues and policy implications. http://futurehealth.ucsf.edu/Content/8877/2010-02_The_Increasing_ Role_of_Medical_Assistants_in_Small_Primary_Care_Physician_ Practice.pdf. Published Feb 2010. Accessed Oct 1, 2013.

16. Ruggiero L, Moadsiri A, Butler $P$, et al. Supporting diabetes selfcare in underserved populations: a randomized pilot study using medical assistant coaches. Diabetes Educ. 2010;36(1):127-131.

17. Ivey SL, Tseng W, Kurtovich E, et al. Evaluating a culturally and linguistically competent health coach intervention for ChineseAmerican patients with diabetes. Diabetes Spectr. 2012;25(2):93-102.

18. Nelson K, Pitaro M, Tzellas A, Lum A. Practice profile. Transforming the role of medical assistants in chronic disease management. Health Aff (Millwood). 2010;29(5):963-965.

19. Chen EH, Thom DH, Hessler DM, et al. Using the Teamlet Model to improve chronic care in an academic primary care practice. J Gen Intern Med. 2010;25(Suppl 4):S610-S614.

20. Willard-Grace R, DeVore D, Chen EH, Hessler D, Bodenheimer T, Thom DH. The effectiveness of medical assistant health coaching for low-income patients with uncontrolled diabetes, hypertension, and hyperlipidemia: protocol for a randomized controlled trial and baseline characteristics of the study population. BMC Fam Pract. 2013;14(27):27.

21. Ramjee V, Sperling LS, Jacobson TA. Non-high-density lipoprotein cholesterol versus apolipoprotein B in cardiovascular risk stratification: do the math. J Am Coll Cardiol. 2011;58(5):457-463.

22. Bodenheimer T, Laing BY. The teamlet model of primary care. Ann Fam Med. 2007;5(5):457-461.

23. Bennett HD, Coleman EA, Parry C, Bodenheimer T, Chen EH. Health coaching for patients with chronic illness. Fam Pract Manag. 2010;17(5):24-29.

24. Szymezak J, Leroy N, Lavalard E, Gillery P. Evaluation of the DCA Vantage analyzer for HbA 1c assay. Clin Chem Lab Med. 2008;46(8): 1195-1198.

25. Lenters-Westra E, Slingerland RJ. Six of eight hemoglobin A1c point-of-care instruments do not meet the general accepted analytical performance criteria. Clin Chem. 2010;56(1):44-52.

26. Dale RA, Jensen LH, Krantz MJ. Comparison of two point-of-care lipid analyzers for use in global cardiovascular risk assessments. Ann Pharmacother. 2008;42(5):633-639.

27. Pickering TG, Hall JE, Appel LJ, et al; Subcommittee of Professional and Public Education of the American Heart Association Council on High Blood Pressure Research. Recommendations for blood pressure measurement in humans and experimental animals: Part 1: blood pressure measurement in humans: a statement for professionals from the Subcommittee of Professional and Public Education of the American Heart Association Council on High Blood Pressure Research. Hypertension. 2005;45(1):142-161.
28. Teoh H, Després JP, Dufour R, et al. A comparison of the assessment and management of cardiometabolic risk in patients with and without type 2 diabetes mellitus in Canadian primary care. Diabetes Obes Metab. 2013;15(12):1093-1100.

29. Schulz KF, Altman DG, Moher D; CONSORT Group. CONSORT 2010 statement: updated guidelines for reporting parallel group randomized trials. Ann Intern Med. 2010;152(11):726-732.

30. NORM. Multiple imputation of incomplete multivariated data under a normal model [software]. Version 2. University Park, PA: The Methodology Center, Penn State; 1999.

31. American Diabetes Association. Standards of medical care in diabetes-2013. Diabetes Care. 2013;36(Suppl 1):S11-S66.

32. Turner BJ, Hollenbeak CS, Liang Y, Pandit K, Joseph S, Weiner MG. A randomized trial of peer coach and office staff support to reduce coronary heart disease risk in African-Americans with uncontrolled hypertension. J Gen Intern Med. 2012;27(10):1258-1264.

33. Vale MJ, Jelinek MV, Best JD, et al; $\mathrm{COACH}$ Study Group. Coaching patients On Achieving Cardiovascular Health (COACH): a multicenter randomized trial in patients with coronary heart disease. Arch Intern Med. 2003;163(22):2775-2783.

34. Holmes-Rovner M, Stommel M, Corser WD, et al. Does outpatient telephone coaching add to hospital quality improvement following hospitalization for acute coronary syndrome? J Gen Intern Med. 2008;23(9):1464-1470.

35. Fisher EB, Strunk RC, Highstein GR, et al. A randomized controlled evaluation of the effect of community health workers on hospitalization for asthma. Arch Pediatr Adolesc Med. 2009;163(3):225-232.

36. Philis-Tsimikas A, Fortmann A, Lleva-Ocana L, Walker C, Gallo LC. Peer-led diabetes education programs in high-risk Mexican Americans improve glycemic control compared with standard approaches: a Project Dulce promotora randomized trial. Diabetes Care. 2011;34(9):1926-1931.

37. Thom DH, Ghorob A, Hessler D, De Vore D, Chen E, Bodenheimer TA. Impact of peer health coaching on glycemic control in lowincome patients with diabetes: a randomized controlled trial. Ann Fam Med. 2013;11(2):137-144.

38. Spencer MS, Rosland AM, Kieffer EC, et al. Effectiveness of a community health worker intervention among African American and Latino adults with type 2 diabetes: a randomized controlled trial. Am J Public Health. 2011;101(12):2253-2260.

39. Margolius $D$, Bodenheimer $T$, Bennett $H$, et al. Health coaching to improve hypertension treatment in a low-income, minority population. Ann Fam Med. 2012;10(3):199-205.

40. Rogers EM. Diffusion of Innovations. 5th ed. New York, NY: Free Press; 2003.

41. Taché S, Hill-Sakurai L. Medical assistants: the invisible "glue" of primary health care practices in the United States? J Health Organ Manag. 2010;24(3):288-305.

42. Bureau of Labor Statistics. Occupational Employment and Wages, May 2012. Section 31-9092: Medical Assistants. http://www.bls.gov/ oes/current/oes319092.htm. Accessed Oct 1, 2013.

43. Merlis M. Health Care Brief: Accountable Care Organizations. HealthAffairs. http://healthaffairs.org/healthpolicybriefs/brief pdfs/healthpolicybrief_23.pdf. Updated Aug 13, 2010. Accessed Nov 6, 2013.

44. Thom D, Hessler D, Willard-Grace R, et al. Health coaching improves low-income patients' experience of care: results from a randomized controlled trial. Paper presented at: Academy Health Annual Research Meeting; June 8-10, 2014; San Diego, CA.

45. Willard-Grace R, DeVore D, Prado C, et al. "Momentum that lasts:" a mixed methods study of clinician experiences with health coaching. Poster presented at: Academy Health Annual Research Meeting; June 8-10, 2014; San Diego, CA.

46. National Council on Quality Assurance. NCQA's Patient Centered Medical Home (PCMH). http://www.ncqa.org/Portals/O/PCMH\%20 brochure-web.pdf. Published Jan 31, 2011. Accessed Dec 10, 2013. 